\title{
The Beverages
}

\author{
Abdelazim Sayed Abdelazim Abdellatif* \\ Food Technology Research Institute (FTRI), Agriculture Research Center, Egypt
}

Submission: January 17, 2018; Published: March 21, 2018

"Corresponding author: Abdeiazmi Sayed, Food Technology Research Institute (FTRI), Agriculture Research Center, Giza, Egypt, Tel: +201228290093/+201210633291; Email: abdelazim_73@yahoo.com

\begin{abstract}
The global commercial beverage market comprises hot drinks, milk drinks, soft drinks (noncarbonated soft drinks (NCSD) and Carbonated Soft Drinks) and alcoholic drinks. Hot drinks include tea and coffee. Soft drinks have five main subcategories. The ingredients and formulation of soft drinks are contents of water up to $98 \% \mathrm{v} / \mathrm{v}$, carbon dioxide $0.30-60 \% \mathrm{~m} / \mathrm{v}$, Sweetener (sugars 7-12 \% m/v), colors (natural or synthetic) 0-70ppm. Cola soft drinks use cola nut from Cola nitida and Cola acuminata trees of Africa as their flavor agent. Non-cola soft drinks usually use citric acid. Flavors used in soft drinks can be divided into two main types based on solubility in water. Water-soluble flavors present no major problems when used in beverages, as there is ample water in a beverage formulation to dissolve and disperse the relatively small amounts of flavor required, Nature-identical and artificial: $0.10-28 \% \mathrm{~m} / \mathrm{m}$ Natural: up to $0.5 \% \mathrm{~m} / \mathrm{m}$, Hydrocolloids (mucilaginous gums) $0.1-0.2 \%$ per GMP and acidulates ( Phosphoric acid, Citric acid $0.030-0.05 \% \mathrm{~m} / \mathrm{v}$,Ascorbic acid, Preservatives Statutory limits apply (e.g. sorbic acid up to $250 \mathrm{ppm}$ in EU). In addition to phosphoric and citric as the major acidulants, some other organic acids such as tartaric, malic and ascorbic acids have special uses in the carbonated soft drinks industry. Nutritional value of soft drinks that these beverages are in the top ten contributing foods for several nutrients, included carbohydrates, vitamins, minerals as well as energy. There are three main areas of particular nutritional significance for soft drinks. The first area is energy. Troiano et al. [1] reported that $20-24 \%$ of energy intake came from beverages. Some soft drinks are formulated to deliver a rapidly assimilated energy boost to the consumer. Soft drinks generally contain soluble sugars, which are easy to administer. The second area of nutritional significance is that of the so-called isotonic drinks, which are of equivalent osmolality to body fluids. The phosphorus content in cola type carbonated beverages could have reduced levels of the active form of vitamin $\mathrm{D}$ and led to a decline in calcium absorption and to bone decalcification, increasing bone fracture risk detected higher calcium in urine after the subjects drank caffeinated cola beverages, indicating that the rise in calcium excretion was due to the caffeine. The high fructose corn syrup (HFCS) intake enhancement was related temporally to the obesity epidemic.
\end{abstract}

Keywords : Beverages; Soft drink; Noncarbonated; Carbonated; Carbon dioxide; Sweeteners; Flavors

\section{Introduction}

Humans maintain their water balance by consuming an equal amount of water to that which is excreted. The body keeps water in a balanced state by controlling intake and excretion. However, the body can suffer from either a negative or a positive water balance. Negative water balance, dehydration, is defined as a reduction of water and salt in varying proportions compared with the normal state, which may be caused by failure to replace obligatory water losses or failure of the regulatory mechanism. Dehydration leads to hypernatremia, which can be caused by one or more of the following: water loss in excess of sodium chloride, inadequate water intake, addition of sodium chloride (salt poisoning), osmotic diuresis (with glucosuria), and diuretic therapy when free water intake is inadequate $[2,3]$. When the body loses salt to a greater extent than that of water, hyponatremic dehydration occurs [2]. Thirst drives humans to drink fluid in order to preserve body fluid homeostasis and survive [4]. A minimum of $1.44 \mathrm{~L}$ of water is needed per day to cover the water lost and to maintain the water balance [5]. Beverages could contribute to the human requirements of water. Troiano et al. [1] reported that $20-24 \%$ of energy intake came from beverages. In addition to fulfilling a basic need, drinks form part of the culture of human society. Types of beverages consumed affect the composition of modern diet [6]. Despite the fact that all beverages contain water, water itself is not classed as a beverage. The word beverage has always been defined as not referring to water. Furthermore, it has been reported that these beverages are in the top ten contributing foods for several nutrients. Milk contributes to energy, protein, fat, calcium and vitamin A intake, while fruit juices contributes to energy, calcium, iron, vitamin C, vitamin $\mathrm{A}$, and fiber intake, and soft drinks contributes in energy and vitamin C (in fortified fruit drinks) intake [7]. 


\section{Types of beverages}

According to Roethenbaugh [8], there are four primary sectors of the global commercial beverage market (Figure 1): hot drinks, milk drinks, soft drinks and alcoholic drinks. Hot drinks, include tea and coffee. Soft drinks have five main subcategories: bottled water; carbonated soft drinks; dilutables, (squash, powders, cordials and syrups); fruit juices (100\% fruit juice and nectars (25-99\% juice content); still drinks, including ready-to-drink (RTD) teas, sports drinks and other noncarbonated products with less than $25 \%$ fruit juice). Alcoholic drinks, including beer, wine, spirits, cider, sake and flavored alcoholic beverages. Amongst the different types of beverages, milk, soft drinks, and fruit juices are the most important and they are consumed in high amounts $[9,10]$. Beverages could be also classified into alcoholic and non alcoholic drinks. An alcoholic beverage is a drink that contains ethanol. A non-alcoholic beverage is a drink that contains little or no alcohol. This category includes low-alcohol beer, nonalcoholic wine, and apple cider if they contain less than $0.5 \%$ alcohol by volume and they are called soft drinks [8].

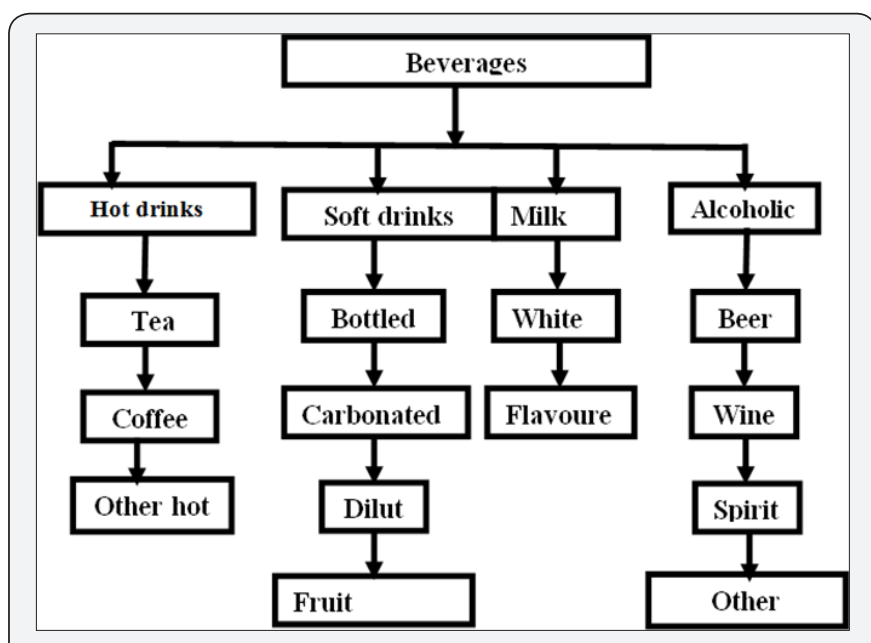

Figure 1: Beverage sectors and segments. Source: Soft drinks world, (2003).

\section{Soft drinks}

There is no single definition available for soft drinks, but it is generally accepted that they are sweetened water-based beverages; usually with a balancing acidity. The term "soft drink" specifies the absence of alcohol in contrast to "hard drink". The term "drink" is neutral but often denotes alcoholic content. Small amounts of alcohol may be present in a soft drink, but the alcohol content must be less than $0.5 \%$ of the total volume if the drink is to be considered non-alcoholic [11]. Soft drinks are refreshing beverages and they are typically formulated from $10-11 \%$ sugar content with about $0.3-0.5 \%$ of acid (usually citric) and flavoring, coloring and chemical preservatives, with the addition of carbon dioxide [12]. A soft drink may also contain caffeine, fruit juice, or both. The widely sold soft drink flavors are cola, cherry, lemon-lime, root beer, orange, grape, vanilla, ginger, fruit punch, and sparkling lemonade. Various other additions can be made, including vitamins and minerals, clouding agents and foaming agents and plant extracts.

\section{Types of soft drinks}

Based on their ingredients, soft drinks are divided into carbonated and non-carbonated soft drinks. None carbonated soft drinks (NCSD): Non carbonated soft drinks are soft drinks without carbon dioxide and sparkling taste and they include fruit punch, fruit drinks, ice tea, coffee with sugar, and sport drinks. Non-carbonated soft drinks do not undergo carbonation process and do not have any sparkling flavor. The sugar used to sweeten the regular soft drinks is either sucrose or high fructose corn syrup. Regular soft drinks have approximately the same amount of sugar as a glass of pineapple or orange juice, 7-14g/100 mL. Diet soft drinks use aspartame, saccharine, acesulfam $\mathrm{K}$, or sucralose as sweeteners A soft drink is slightly acidic in order to give pleasant tartness to the product and preserve it. The most common acidulants in soft drinks are citric acid and phosphoric acid [13].

\section{Carbonated soft drinks (CSD)}

Carbonated Soft Drinks are beverages with added carbon dioxide that gives an effervescent taste to the beverages. Carbonated soft drinks are further divided into colas and noncolas, as well as diet and regular soft drinks. The cola-flavored carbonated beverages usually contain added phosphoric acid as acidulant because it can strengthen the acidity. Phosphoric acid has the same characteristics as the cola flavors, which are dry and sometimes balsamic $[1,14]$. Cola soft drinks use cola nut from Cola nitida and Cola acuminata trees of Africa as their flavor agent. Non-cola soft drinks usually use citric acid as acidulant [15]. Other categories of soft drinks are ready-to-drink soft drinks and dilute-to-taste soft drinks which are concentrated or in powder form [16].

\section{Nutritional value of soft drinks}

Water is an essential need for body. The need for water exists at the molecular, cellular, metabolic and functional levels. Water is a major solvent for the organic and inorganic chemicals involved in the biochemical reactions that are essential to life. Water is the principle medium that transports nutrients via body fluids to cell walls and act as carrier of nitrogenous waste products from the cells for ultimate elimination $[17,18]$. Water also is a good regulator for body heat [19]. About 60\%, by weight, of a person body is water [20]. A normal person experiences symptoms of dehydration when $5-10 \%$ of the body weight is lost as water and not soon replaced. Thirst drives human to drink fluid in order to preserve body fluid homeostasis and survive [4]. Water may be obtained through several common beverages: plain water, bottled water, fruit and vegetable juices, fruit drinks, soft drinks, syrup, stimulant beverages, and milk [21]. Several kinds of beverages are consumed not for food value but rather for thirst - quenching properties or for stimulating. Soft drinks are an essential vehicle for hydration. Soft drinks 
are usually absorbed more readily than water (because of their osmolality), can replace lost salts and energy quickly and are rapidly thirst quenching. Their balance of sweetness and acidity, coupled with pleasant flavors, makes them attractive to all ages of consumers [22]. Soft drinks and fruit juices are important beverages for adolescents because they are consumed at high amounts [9,10]. Furthermore, Shachman [23] reported that these beverages are in the top ten contributing foods for several nutrients, including carbohydrates, vitamins, minerals as well as energy. There are three main areas of particular nutritional significance for soft drinks. The first area is energy Troiano et al. [1] reported that $20-24 \%$ of energy intake came from beverages. Some soft drinks are formulated to deliver a rapidly assimilated energy boost to the consumer. Soft drinks generally contain soluble sugars, which are easy to administer. The second area of nutritional significance is that of the so-called isotonic drinks, which are of equivalent osmolality to body fluids. They promote extremely rapid uptake of body salts and water, and are very important products for sportspeople and others requiring almost instant hydration. Third, soft drinks have been widely formulated to low-calorie forms and these are now available for those who wish to enjoy such beverages and yet minimize their calorific intake. Other nutritional benefits that are claimed by some producers include the delivery of essential vitamins and minerals, especially to children.

\section{Adverse effects of soft drinks}

On the negative side, soft drinks have been claimed to have some adverse effects on human health. Wyshak [24] showed that all kinds of soft drink intake enhanced the bone fracture risk. Meanwhile, more recently, McGartland et al. [25] reported that the consumption of carbonated soft drinks did not affect bone health. The mechanism of this phenomenon is not known yet. Furthermore, cola beverage effects were more pronounced in more active girls and children. The phosphorus content in cola type carbonated beverages could have reduced levels of the active form of vitamin D and led to a decline in calcium absorption and to bone decalcification, increasing bone fracture risk $[24,26,27]$. The calcium: phosphorus ratio is a significant risk factor for bone fractures [27,28]. All cola beverages contain 40 to $70 \mathrm{mg}$ phosphorus per $12 \mathrm{oz}$ serving [29]. Studies indicated that caffeine could contribute to bone health. Heaney \& Rafferty [30] detected higher calcium in urine after the subjects drank caffeinated cola beverages, indicating that the rise in calcium excretion was due to the caffeine. The authors proved that the mechanism of how phosphorus in soft drinks may impact on calcium metabolism is not through urinary calcium losses and they stated that drinking fruit juice can also lead to bone fracture. High potassium citrate in fruit juices was found to lower bone desorption Tylavsky et al. [31] and Marangella et al. [32]. The effect of sugars content of soft drinks was studied. Nguyen et al. [33] detected a negative impact of sugar on bone. Soft drinks contain a lot of sugar, especially fructose, but the diet soft drinks use primarily aspartame. Glucose intakes provoked a decrease in phosphatemia (high concentration of inorganic phosphates in blood) since phosphate followed glucose uptake into cells as required for glucose phosphorylation. The reduction of serum phosphate could stimulate mineral bone release, causing a rise in calcemia (excess calcium in blood). The effect of glucose to bone could be similar with the effect of fructose. It was found that a high fructose diet $(20 \%$ of total calories) causes an increase in urinary loss of phosphorus and negative phosphorus balance. The prevalence of dental erosion and decay in human teeth has increased dramatically in the few decades as a result of an increasing consumption of soft drinks and commercial fruit juices. Soft drinks have acquired a reputation for being an agent in the development of dental caries. Johansson [34] claimed that dental erosion rises when sugar residues remain in the mouth or when especially young children have an acidic drink almost constantly in their mouths. It is perhaps now accepted that the dental caries problem is related more to the misuse, or even abuse, of soft drinks than to the effects of normal consumption of such products. Not only beverages, but also the consumption of acidic foodstuffs plays a major role in the development of erosion. Erosion is defined as the loss of dental hard tissue resulting from non-bacterial chemical attack usually involving acidic substances. The amount of mineral dissolved during the erosion depends on several factors including $\mathrm{pH}$, the buffering effect, and the length of the exposure time. The buffering effect is the concentration of acids in the beverages or the ability of an acidic solution to keep its $\mathrm{pH}$ unaffected in dissolving enamel apatite and diluting with saliva. The stronger the buffering effect, the more mineral will be dissolved before the equilibrium $\mathrm{pH}$ can be reached and stop the dissolution. However, the presence of a certain quantity of calcium, phosphate and fluoride in the drinks may have protective effect against the dissolution [35-37]. Heller et al. [38] revealed that cola consumption more than three times a week increased the risk of the erosion to three times. Meanwhile, Forshee \& Storey [39] found that regular soft drink consumption was not associated with dental cavities among people under the age of 25 years. Soft drinks influence dental health by providing sugar and acid. Acid in soft drinks may contribute to the erosion of teeth. Two characteristics in soft drinks that determine their erosive potential; the initial $\mathrm{pH}$ and the buffering capacity. The orange juice with its high buffering effect than the lemonade-like soft drinks (Schweppes ${ }^{\mathrm{TM}}$, Coca-cola ${ }^{\mathrm{TM}}$, and Pepsi ${ }^{\mathrm{TM}}$ ) performed a considerable buffering effect, but the $\mathrm{pH}$ of the soft drinks was lower than the orange juice $\mathrm{pH}$ [40]. More recently, Low \& Alhuthali [41] suggest that the increasing weight loss in tooth enamel during dental erosion in soft drinks can be attributed to the continuous leaching of calcium ions, in addition to phosphorus. Daniela et al. [42] assessed the erosive potential of a light cola drink when compared to a regular one in situ/ex vivo. and suggested that the light cola drink is less erosive than the regular one. Trails were made by the soft drink manufacturers to improve their drinks properties from a dental perspective. A 
reduction in the erosive potential of some acidic soft drinks has been achieved through the careful manipulation of $\mathrm{pH}$, titratable acidity and the addition of calcium [43]. Studies showed that it is possible to modify the formulation of carbonated soft drinks to minimize dental erosion $[44,45]$. In the same trend, Hooper et al. [46] suggested that the technology of adding calcium with appropriate $\mathrm{pH}$ adjustment in the processing of soft and carbonated drinks markedly reduce erosive potential, This technology could be applied to sports drinks to the same purpose [47]. Melissa et al. [48] evaluated that the effect of iron on the acid demineralization of enamel blocks by soft drinks in vitro and concluded that iron at $10 \mathrm{mmol} / \mathrm{L}$ significantly reduced the harmful effects. The contribution of soft drink intake to obesity was studied. Soft drink intake was identified as one of the contributory factors to obesity or weight gain [49]. Energy given by a sugar content of beverage was more preserved by the body than a mix nutrient beverage of the equal volume and energy content because these kinds of beverages had smaller Table 1: Soft drink components*. thermic effect [50]. There was also a positive relationship between sugar-sweetened drink intakes and both greater weight gain and risk of type 2 diabetes [51]. Soft drinks contained high fructose corn syrup and glucose that could enhance the energy over consumption .The high fructose corn syrup (HFCS) intake enhancement was related temporally to the obesity epidemic, and too much HFCS in soft drinks might have a role in the obesity epidemic [52].

\section{Ingredients and formulation of soft drinks}

The simplest form of soft drink contains a mix of the basic nutritional components; sugars, acids in water with flavoring, coloring and chemical preservatives, in addition to carbon dioxide to render the product 'sparkling', 'effervescent' or 'fizzy'. Sadecka \& Polonsky [39] reported a review on the determination of various compounds in beverage samples, including soft drinks, using electrophoretic methods. Taylor [53] summarized the components of soft drinks as shown in Table 1.

\begin{tabular}{|c|c|}
\hline Component & Typical Use Level \\
\hline Water & Up to $98 \% \mathrm{v} / \mathrm{v}$ \\
\hline Sugars & \begin{tabular}{c}
$7-12 \% \mathrm{~m} / \mathrm{v}$ \\
\hline Fruit juice
\end{tabular} \\
\hline High-intensity sweeteners & $\begin{array}{c}\text { Use based upon sucrose equivalence (e.g. aspartame might be } \\
\text { employed at } 0.40-6 \% \mathrm{~m} / \mathrm{v} \text { as sole sweetener). }\end{array}$ \\
\hline Carbon dioxide & $0.30-60 \% \mathrm{~m} / \mathrm{v}$ \\
\hline Acids (e.g. citric) & $0.030-0.05 \% \mathrm{~m} / \mathrm{v}$ \\
\hline Flavors & Nature-identical and artificial: $0.10-28 \% \mathrm{~m} / \mathrm{m}$ Natural: up to $0.5 \% \mathrm{~m} / \mathrm{m}$ \\
\hline Emulsion (flavor, color, cloud etc.) & $0.1 \% \mathrm{~m} / \mathrm{v}$ \\
\hline Colors (natural or synthetic) & $0-70 \mathrm{ppm}$ \\
\hline Preservatives & Statutory limits apply (e.g. sorbic acid up to $250 \mathrm{ppm}$ in EU) \\
\hline Antioxidants (e.g. BHA, ascorbic acid) & Less than $100 \mathrm{ppm}$, subject to user-country legislation \\
\hline Quillaia extract (saponins) & Up to 200mg/l (EU), up to $95 \mathrm{mg} / \mathrm{l}$ (USA) \\
\hline Hydrocolloids (mucilaginous gums) & $0.1-0.2 \%$ per GMP, minimum amount required to create desired effect \\
\hline Vitamins/Minerals & allowed daily intake applies \\
\hline
\end{tabular}

\section{Water}

Water is the main component of a soft drink, usually accounts between 85 and $95 \%$ of the product and acts as a carrier for the other ingredients. Water quality must conform to rigid requirements and not interfere with the taste, appearance, carbonation or other properties of the drink. It may be necessary to carry out treatment to improve the quality of the water used in the manufacture of soft drinks. Water should be free from: high levels of elements and mineral salts; objectionable tastes and odors; organic material. It is very important that water should also be clear; colorless and free from dissolved oxygen and microorganism [53].

\section{Sweeteners}

The profile of bulk and intense sweetener used in soft drinks has changed significantly over the last 10-15 years due to several reasons, including; reducing cost, developing new formulations and increasing consumer awareness of health leading to an increased number of low- and reduced-sugar formulations [54]. Sweeteners used in soft drink may be classified as carbohydrate sweeteners and artificial sweeteners. Carbohydrate-based sweeteners still represent the largest share of the global sweetener market and account for $81 \%$ of sweetener usage [55]. A number of carbohydrate sweeteners are used in soft drinks to provide different attributes, including sweetness, mouthfeel, stability and, in some cases, color. Sucrose is regarded as the standard for a sweet taste. In soft drinks, glucose syrups are used to provide sweetness and mouthfeel to products and occasionally specific physiological properties in sports and energy drinks. Glucose syrups are significantly less sweet than corresponding sucrose solutions (glucose has a relative sweetness of 0.6), unless they have a high fructose content. Fructose can also be 
used as a sugar substitute in soft drinks [53]. High-fructose corn syrups dominate the carbohydrate-sweetened soft drinks sector in some markets - notably in the United States [54]. Fructose is unique among known natural sugars in being sweeter than sucrose. Fructose has some interesting physiological properties. It is a monosaccharide sugar with energy content of $4 \mathrm{kcals} / \mathrm{g}$ and due to its increased sweetness it can be used at lower levels than sucrose. Fructose is slowly absorbed and metabolized by the body, independent of insulin production, and does not cause rapid raises in blood glucose after ingestion. It is, therefore, suitable for diabetics and also for use in soft drinks intended to act as a slower, more sustained energy source. Owing to its limited effect on blood glucose, it is a low glycaemic index sweetener (compared with glucose). This is an area of increased nutritional interest and may be a stimulus to the greater use of fructose in soft drinks. Fructose has also been shown to have an increased satiety effect, compared with other sweeteners [56]. Mineral absorption (iron and calcium) has also been shown to be positively affected by the incorporation of fructose into the diet [57]. In addition to carbohydrate sweeteners, the use of intense sweeteners in soft drinks has increased dramatically over the last 25 years. The use of intense sweeteners in soft drinks was given a further boost due to the requirement for a minimum carbohydrate in low-calorie products. Today, the main intense sweeteners in use in soft drinks are acesulfame $\mathrm{K}$, aspartame, saccharin and cyclamate [58]. However, it has been reported that substitution of sucrose by intense sweeteners often changes the flavor of the beverage [59]. Products were reformulated to incorporate blends of intense sweeteners and low levels of carbohydrate sweeteners (around 0.5-3.0 Brix) to deliver cost savings without compromising taste quality. Over time, and as the use of intense sweeteners expanded, optimization of the sweetener blends continued to deliver excellent tasting products. Currently, about $50 \%$ of all beverages contain intense sweeteners, even though the diet market is only $25 \%$ of the total [55].

\section{Acidulants}

A soft drink is slightly acidic in order to give pleasant tartness to the product and preserve it. The most common acidulants in soft drinks are citric acid and phosphoric acid [13]. The use of acidulants is an essential part of beverage formulation, with the acid component usually third in order of concentration. Acidulants performs a variety of functions in addition to their primary thirst-quenching properties, which are the result of stimulation of the flow of saliva in the mouth. Stampanoni [60] studied the influence of acid and sugar content on sweetness, sourness and the flavor profile of beverages and found that acid addition increased sourness and decreased sweetness, whereas sugar increased sweetness and depressed sourness. Melissa et al. [48] investigated the influence of fruit acids (in particular, citric and malic acids) on people's perception of the identity and intensity of a variety of different fruit flavored beverages. Because it reduces $\mathrm{pH}$, an acidulant can act as a mild preservative and in some respects as a flavour enhancer, depending on the other components present. In addition, by functioning as a synergist to antioxidants such as ascorbic acid, acidulants can indirectly prevent discoloration. Organic acids such as citrate and malate, and inorganic anions such as phosphates are important due to their function as acidifiers or flavor enhancers [20]. An HPLC method was developed for the determination of citric, malic, oxalic and tartaric acids in soft drinks [54].

Phosphoric acid is the only inorganic acid to be widely used in food preparations as an acidulant. In the soft drinks industry its use is confined almost entirely to cola-flavored carbonated beverages, where its special type of astringent acidity complements the dry, sometimes balsamic, character of cola drinks. Phosphoric acid has a drier, and perhaps sharper, flavor than either citric or tartaric acid, tasting rather of flat 'sourness', in contrast with the sharp fruitiness of citric acid. It therefore appears to blend better with most non-fruit drinks [53].

Citric acid is the most widely used acid in fruit-flavored beverages. It has a light fruity character that blends well with most fruit flavors, which is to be expected as it occurs naturally in many fruit types. Hansson et al. [61] investigated the influence of adding citric and phosphoric acids in variable amounts to a soft drink model system on the release of six flavor compounds. They found that the high concentrations of the acids decreased the release of esters, probably because of the presence of large amounts of the dissociated form of the acids.

Ascorbic acid is used not only as an acidulant but also as a stabiliser within the soft drinks system, and its antioxidant properties serve to improve the shelf-life stability of flavor components. Many of the ingredients used in flavorings are susceptible to oxidation, particularly aldehydes, ketones and keto-esters. Ascorbic acid shields these from attack by being preferentially oxidized and lost, leaving the flavor component unaffected. Meanwhile, a disadvantage of ascorbic acid is its effect on some colours in the presence of light. In the case of azo-colours, such as carmoisine, a light-catalysed reaction occurs, resulting in the disappearance of colour and bleaching of the characteristic hue associated with some soft drinks [58]. In addition to phosphoric and citric as major acidulants, some other organic acids such as tartaric, malic and ascorbic acids have special uses in the carbonated soft drinks industry. Tartaric acid with its sharper flavor than citric may therefore be used at a slightly lower level to give equivalent acidity [59]. Similarly, malic acid is slightly stronger than citric in perceived acidity, imparting a fuller, smoother fruity flavor. Malic acid is the preferred acidulant in low-calorie drinks and in cider and apple drinks, enhancing flavor and stabilizing color in carbonated drinks. Malic acid may also be used to mask the off-taste of some sugar substitutes. Blends of malic and citric acids are said to exhibit better taste characteristics than either acidulant individually [55]. 


\section{Carbon dioxide and carbonation process}

Beverages containing carbon dioxide are, nowadays, very popular products. The addition of $\mathrm{CO}_{2}$ renders the product 'sparkling', 'effervescent' or 'fizzy', and the acid formed (carbonic acid) from carbon dioxide enhances the sharpness of taste [62]. Consumers enjoy their "pleasurable and sought after" sensation, despite the fact that they can be irritating, or even painful for some people. The sensation elicited by carbonated drinks are either of mechanical origin, due to the bursting $\mathrm{CO}_{2}$ bubbles stimulating mechanoreceptors on tongue, or of chemogenic origin by formation of carbonic acid in a reaction catalysed by carbonic anhydrase, which stimulates polymodal nociceptors in the oral cavity [63]. It has been reported that bubbles appear when concentration levels of $\mathrm{CO}_{2}$ are 3-5 times higher than the saturation equilibrium value and depend on the pre - existing gas - liquid interfaces $[64,65]$. Numbers and sizes of these bubbles also have a sensory impact on the beverage, enhancing mass transport of $\mathrm{CO}_{2}$ when the bubbles impinge upon the tongue and increase the "tingling" sensation $[66,67]$. The modification of the composition of soft drinks may dramatically affect the visual or taste perception of effervescence of the drink $[66,67]$. Also, the addition of $\mathrm{CO}_{2}$ provides a very effective antimicrobial effect, especially against yeasts and moulds. Carbon dioxide is effective against yeasts because it tends to suppress the production of more $\mathrm{CO}_{2}$ as a byproduct of the fermentation of sucrose to ethanol. It deprives moulds of the oxygen that most of them require for growth. Good hygiene standards are the norm in most soft drinks bottling operations today, and it is possible to produce carbonated drinks without chemical preservatives by flash-pasteurizing the syrup before it is mixed with carbonated water. The risk of microbiological spoilage is then low, but where multiserving containers are used the risk is increased because of the potential for subsequent contamination [54]. Carbon dioxide levels in carbonated soft drinks vary widely and are usually expressed as 'volumes of $\mathrm{CO}_{2}$ gas' (i.e. the volume of carbon dioxide contained in solution in one volume of product). Lightly carbonated products will contain around 2.0-3.0 volumes of the gas; moderate carbonation usually refers to about 3.5-4.0 volumes and high carbonation levels are around 4.5-5.0 volumes. Large bottles that are likely to become partly full will be relatively highly carbonated, and mixer drinks contain among the highest carbonation levels because the resultant mixture (e.g. gin and tonic) needs to have a satisfactory residual level of dissolved carbon dioxide [12]. Carbonation is the process of adding carbon dioxide gas to the beverage to produce carbonated soft drinks. Carbonation can be achieved by injecting the gas into a pressure - sealed vessel $[66,67]$. As the carbonation system is pressure - sealed, gaseous injection increases the internal pressure, and thereby the $\mathrm{CO}_{2}$ solubility. Up to $9 \mathrm{~g} / \mathrm{l}$ of $\mathrm{CO}_{2}$ can be dissolved, which is the limit for highly carbonated drinks such as tonic water. On the other hand, depressing the system lowers the $\mathrm{CO}_{2}$ concentration in the headspace, causing gas desorption $[66,67]$. In carbonated drinks industry, gas can be injected continuously through a venture in the liquid flow. Mixing is thus much more efficient and higher concentration levels can be reached. The beverage is collected in pressurized tanks or directly in bottles. Descoins et al. [68] suggested a unit to monitoring the carbonation process of beverages in a laboratory scale with on line measurement of dissolved $\mathrm{CO}_{2}$

\section{Flavors}

A soft drink is slightly acidic in order to give pleasant tartness to the product and preserve it. The most common acidulants in soft drinks are citric acid and phosphoric acid [13]. Colaflavored carbonated beverages use phosphoric acid as acidulant because it can strengthen the acidity and cola flavor at very low costs. Phosphoric acid has the same characteristics as the cola flavors, which are dry and sometimes balsamic [14,53]. Cola soft drinks use cola nut from Cola nitida and Cola acuminata trees of Africa as their flavor agent [15]. Non-cola soft drinks usually use citric acid. Flavors used in soft drinks can be divided into two main types based on solubility in water. Water-soluble flavors present no major problems when used in beverages, as there is ample water in a beverage formulation to dissolve and disperse the relatively small amounts of flavor required [12]. A flavor containing oil components that are not soluble in water cannot be used directly in the formulation. These components would separate out in the beverage and form a neck-ring in the beverage or, sometimes, in clear beverages, be seen as tiny suspended particles, giving the drink an unsightly appearance. To overcome this problem, an insoluble flavor is prepared by a flavor house in the form of an emulsion that can then be used in a soft drink formulation. These are the flavor emulsions that are used for flavoring the beverage as well as giving the beverage its cloudy appearance. It goes without saying that a flavor emulsion cannot be used in a clear beverage. Should a person want to use a particular water-insoluble flavor in a clear beverage, it is possible that the flavor house supplier may be able to modify the flavorant into a water-soluble form or supply a water-soluble variant of that particular flavor [52]. Most soft drink flavorants are used in liquid form, but powdered spray-dried flavors can also be used. Spray-dried flavors are mostly used in powdered instant beverage products. Again, the water-solubility factor must be taken into consideration. The flavor component of a typical carbonated soft drink (CSD) formulation may amount to anything from 10 to $50 \%$ of the total raw materials cost, including the sugar sweetener. Thus, the cost contribution level can sometimes be of great significance in the beverage formulation design. Therefore, it will depend on the sophistication involved in the product design, which, in turn, may depend on the target market as well as on the company's profit margin policies. All in all, flavorants present a costing factor that should not be ignored in beverage formulations, both in current existing products as well as in new product development. Flavorants are sometimes used in natural fruit juices as boosters of the natural fruit flavor. Fruit juice blends may contain such flavor boosters for the juices of the fruit species in the blend that are not in major proportions 
of that particular fruit mix. Local food laws govern the use of flavors in natural juice beverages, and these should be consulted before including them in formulations of these products. Food laws may also govern the way flavors are described in the label's ingredient list, especially focusing on the "natural versus artificial" aspects that may be involved. Food legislation may also extend to the way the beverage may be described on the label. A flavouring essence is a traditional flavouring product prepared by washing a selected oil blend (predominately citrus oils) with an aqueous alcoholic solvent mixture (e.g. 60\% ethanol /40\% water). It is an extraction process in which the aqueous extract phase becomes the flavouring. The process is carried out under cool temperatures, for example, $5-10{ }^{\circ} \mathrm{C}$, either batch-wise or by counter-current extraction. The soluble oxygenated flavouring constituents present in the essential oil blend (e.g. citral in lemon oil) are effectively partitioned between the two phases of the mixture. The low temperatures employed ensure that the transfer of any oil into the hydro-alcoholic phase is minimized as a poorly processed essence will tend to cloud when used in the drink formulation. Carbonated and noncarbonated soft drinks may be made from anise, cinnamon, ginger and fennel extracts. The obtained results for organoleptic evaluation of carbonated soft drink and noncarbonated made from anise, cinnamon, ginger and fennel extracts indicated that the carbonated had higher overall acceptability values than noncarbonated soft drink. They are rich sources of some compounds (minerals, vitamin, organic acids and phenolic compounds) that are essential and required for humans. The study also confirmed the good microbiological stability of carbonated and noncarbonated soft drinks made from anise, cinnamon, ginger and fennel extracts. It has been suggested in future studies the effect of storage on carbonated and noncarbonated soft drink [69,70-75].

\section{References}

1. Troiano RP, Briefel RR, Carroll MD, Bialostosky K (2000) Energy and fat intakes of children and adolescents in the United States: data from the National Health and Nutrition Examination Surveys. Am J Clin Nutr 72(5 Suppl): 1343S-1353S.

2. Fiordalisi I, Finberg L (2003) Diarrhea and Dehydration. In: Perkin RM, Swift JD, Newton DA (Eds.), Pediatric Hospital Medicine. Lippincott Williams \& Wilkins, Philadelphia, USA, pp.191-198.

3. Lorenz JM, Kleinman LI (2003) Physiology and Pathophysiology of Body Water and Electrolytes. In: Kaplan LA, Pesce AJ, Kazmierczak SC (Eds.), Clinical chemistry: theory, analysis, correlation. Mosby, Inc, Missouri, USA, pp. 452-453.

4. McKinley MJ, Johnson AK (2004) The physiological regulation of thirst and fluid intake. News in Physiological Science 19: 1-6.

5. Valtin H (2002) Drink at least eight glasses of water a day." Really? Is there scientific evidence for "8 x 8". Am J Physiol Regul Integr Comp Physiol 283(5): R993-R1004.

6. Stubbs RJ, Whybrow S (2004) Energy density, diet composition and palatability: influences on overall food energy intake in humans. Physiol Behav 81(5): 755-764.

7. Zohouri FV, Rugg-Gunn AJ, Fletcher ES, Hackett AF, Moynihan PJ, et al. (2004) Changes in water intake of Northumbian adolescents 1980 to 2000. British Dental Journal 196(9): 547-552.
8. Roethenbaugh G (2005) Ingredients. In Chemistry and Technology of Soft Drinks and Fruit Juices. Ashurst PR (Eds.), Sheffield Academic Press, England, pp. 15-34.

9. Forshee RA, Storey ML (2003) Total beverage consumption and beverage choices among children and adolescents. International Journal of Food Science and Nutrition 54(4): 297-307.

10. Rampersaud GC, Bailey LB, Kauwell GP (2003) National Survey beverage consumption data for children and adolescents indicate the need to encourage a shift toward more nutritive beverages. J Am Diet Assoc 103(1): 97-100.

11. Anon (2011) Electronic Code of Federal Regulations. United States Government.

12. Ashurst PR (2005) In Chemistry and Technology of Soft Drinks and Fruit Juices. Sheffield Academic Press, England, pp. 90-128.

13. National Soft Drink Association (2003) What's in Soft Drink.

14. Jorge K (2003) Soft Drinks. In: Caballero B, Trugo L, Finglas P (Eds.), Encyclopedia of Food Sciences and Nutrition. Academic Press, USA, pp. 5346-5352.

15. Grivetti LE, Wilson T (2004) A brief history of human beverage consumption. In: Wilson T \& Temple NJ (Eds.), Beverages in Nutrition and Health. Humana Press, Inc, New Jersey, USA, pp. 3-18.

16. Ashurst PR (1998) Introduction in (P.R. Ashurst, Ed). Chemistry and Technology of Soft Drinks and Fruit Juices, Sheffield Academic Press, England, pp.1-15.

17. Kleiner SM (1999) Water, an essential but overlooked nutrient. J Am Diet Assoc 99(2): 200-206.

18. Sheng HP (2000) Body Fluids and Water Balance. In: Stipanuk MH (Ed.), Biochemical and Physiological Aspects of Human Nutrition. WB Saunders Company, Pennsylvania, USA.

19. Whitmire SJ (2004) Water, electrolytes, and acid-base balance. In: Mahan LK, Escott-Stump S (Eds.), Krause's food, nutrition, \& diet therapy. Elsevier, Philadelphia, pp. 165-179.

20. Institute of Medicine (IOM) (2004) Dietary Reference Intakes for Calcium, Phosphorus, Magnesium, Vitamin D, and Fluoride. National Academy Press, Washington, USA.

21. The Swiss Association for Nutrition (2003) Water and Non-Alcoholic Drinks.

22. Steinmetz KA, Potter JD (1996) Vegetables, fruit, and cancer prevention. J Am Diet Assoc 96(10): 1027-1039.

23. Shachman M (2005) The soft drinks companion: a technical handbook for the beverage industry. CRC Press, Boca Raton London New York Washington, USA.

24. Wyshak G (2000) Teenaged girls, carbonated beverage consumption, and bone fractures. Archives of Pediatric and Adolescent Medicine 154(6): 610-613.

25. McGartland C, Robson PJ, Cran G, Savage MJ, Watkins D, et al. (2003) Carbonated soft drink consumption and bone mineral density in adolescence: The Northern Ireland Young Hearts Project. Journal of Bone and Mineral Research 18(9): 1563-1569.

26. Mazariegos-Ramos E, Guerrero-Romero F, Rodriguez-Moran M, Lazcano- Burciaga G, Paniagua R, et al. (1995) Consumption of soft drinks with phosphoric acid as a risk factor for the development of hypocalcemia in children: A case-control study. Journal of Pediatric 126(6): 940-942.

27. Guerrero-Romero F, Rodriguez-Moran M, Reyes E (1999) Consumption of Soft Drinks with Phosphoric Acid as a Risk Factor for the Development of Hypocalcemia in Postmenopausal Women. J Clin Epidemiol 52(10): 1007-1010. 
28. Petridou E, Karpathios T, Dessypris N, Simou E, Trichopoulos D (1997) The role of dairy products and non alcoholic beverages in bone fractures among achoolage children. Scandivanian Journal of Social Medicine 25(2): 119-125.

29. Massey LK, Strang MM (1982) Soft drink consumption, phosphorus intake, and osteoporosis. J of American Dietetic Association 80(6): 581-583.

30. Heaney RP, Rafferty K (2001) Carbonated beverages and urinary calcium excretion. American Journal Clinical Nutrition 74(3): 343-347.

31. Tylavsky FA, Holliday K, Danish R, Womack C, Norwood J, et al. (2004) Fruit and vegetable intakes are an independent predictor of bone size in early pubertal children. Am J Clin Nutr 79(2): 311-317.

32. Marangella M, Di Stefano M, Casalis S, Berutti S, D’Amelio P, et al. (2004) Effects of potassium citrate supplementation on bone metabolism. Calcif Tissue Int 74(4): 330-335.

33. Nguyen UN, Dumoulin G, Henriet MT, Regnard J (1998) Aspartame ingestion increases urinary calcium, but not oxalate excretion, in healthy subject. J Clin Endocrinol Metab 83(1): 165-168.

34. Johansson AK, Johansson A, Birkhed D, Omar R, Baghdadi S, et al. (1997) Dental erosion associated with soft-drink consumption in young Saudi men. Acta Odontol Scand 55(6): 390-397.

35. Larsen MJ, Nyvad B (1999) Enamel erosion by some soft drinks and orange juice relative to their $\mathrm{pH}$, buffering effect and contents of calcium phosphate. Caries Res 33(1): 81-87.

36. Lussi A, Jaeggi T, Zero D (2004) The role of diet in the aetiology of dental erosion. Caries Res 38(Suppl 1): 34-44.

37. Tahmassebi JF, Duggal MS, Malik-Kotru G, Curzon MEJ (2006) Soft drinks and dental health: A review of the current literature. J Dent 34(1): 2-11.

38. Heller KE, Burt BA, Eklund SA (2001) Sugared soda consumption and dental caries in the United States. Journal of Dental Research 80(10): 1949-1953.

39. Forshee Sadecka J, Polovka M (2008) Multi-experimental study of c-radiation impact on oregano (Origanum vulgare L.). Journal of Food and Nutrition Research 2: 85-91.

40. Larsen MJ, Richards A (2002) Fluoride is unable to reduce dental erosion from soft drinks. Caries Research 36(1): 75-80.

41. Low IM, Alhuthali A (2008) In-situ monitoring of dental erosion in tooth enamel when exposed to soft drinks. Materials Science and Engineering C 28: 1322-1325.

42. Daniela R, Heitor MH, Ana CM, Annette W, Maria Ad AMM, et al. (2009) Light cola drink is less erosive than the regular one: An in situ/ex vivo study J of dentistry 37(2): 163-166.

43. West NX, Hughes J, Parker D, Newcombe RG, Addy M ( 1999) Development and evaluation of a low erosive blackcurrant drink 2. Comparison with a conventional blackcurrant drink and orange juice. J Dent 27: 341-344.

44. West NX, Hughesa JA, Parkerb DM, Moohan M, Addy M (2003) Development of low erosive carbonated fruit drinks 2. Evaluation of an experimental carbonated blackcurrant drink compared to a conventional carbonated drink. J Dent 31(5): 361-365.

45. West NX, Hughes JA, Parker D, Weaver LJ, Moohan M, et al. (2004) Addy M. Modification of soft acidic drinks with xanthan gum to minimise erosion: a study in situ. British Dental J 196(8): 478-481.

46. Hooper S, West NX, Sharif N, Smith S, North M, et al. (2004) Acomparison of enamel erosion by a new sports drink compared to two proprietary products: a controlled, crossover study in situ. Journal of Dentistry 32(7): 541-545.
47. Hooper SM, Hughes JA, Newcombe RG, Addy M, West NX (2005) A methodology for testing the erosive potential of sports drinks. J Dent 33(4): 343-348.

48. Melissa TK, Sílvia HdC, Sales P, Marília ARB (2007) Effect of iron on acid demineralisation of bovine enamel blocks by a soft drink. Archives of oral biology 52(11): 1109-1111.

49. Berkey CS, Rockett HR, Field AE, Gillman MW, Coldit, GA (2004) Sugaradded beverages and adolescent weight change. Obesity Research 12(5): 778-88.

50. St-Onge MP, Rubiano F, Denino WF, Jones Jr A, Greenfield D, et al. (2004) Added thermogenic and satiety effects of a mixed nutrition vs a sugaronly beverage. Int J Obes Relat Metab Disord 28(2): 248-253.

51. Schulze MB, Manson JE, Ludwig DS, Colditz GA, Stampfer MJ, et al. (2004) Sugar-sweetened beverages, weight gain, and incidence of type 2 diabetes in young and middle-aged women. JAMA 292(8): 927-934.

52. Bray GA, Nielsen SJ, Popkin BM (2004) Consumption of high-fructose corn syrup in beverages may play a role in the epidemic of obesity. American J of Clinical Nutrition 79(4): 537-543.

53. Taylor RB (2005) Other beverage ingredients. In: Ashurst PR (Ed.), Chemistry and Technology of Soft Drinks and Fruit Juices. Sheffield Academic Press, England, pp. 90-128.

54. O’Donnell K (2005) Carbohydrate and intense sweeteners in Chemistry and Technology of Soft Drinks and Fruit Juices. Ashurst PR (Ed.), Sheffield Academic Press, England, pp. 90-128.

55. Cosgrove J (2003) The Evolution of Category Management. Beverage Industry $94(2): 50$.

56. Spitzer L, Rodin J (1987) Chemistry and Technology of Soft Drinks and Fruit Juices (2005). Ashurst PR (Eds.), Sheffield Academic Press, England, pp. 90-128.

57. Holbrook JT, Smith JC, Reiser S (1989) Dietary fructose or starch: effects on copper, zinc, iron, manganese, calcium and magnesium balances in humans. Am J Clin Nutr 49(6): 1290-1294.

58. Zhao L, Beverly J, Tepper (2007) Perception and acceptance of selected high-intensity sweeteners and blends in model soft drinks by propylthiouracil (PROP) non-tasters and super-tasters. Food Quality and Preference 18(3): 531-540.

59. Nahon D, Jacques F, Roozen P, De Graaf C (1998) Sweetness flavour interactions in soft drinks. Food Chemistry 56(3): 283-289.

60. Stampanoni CR (1993) Influence of acid and sugar content on sweetness, sourness and the flavor profile of beverages and sherbets. Food Quality \& Preference 4(3): 169-176.

61. Hansson A, Andersson J, Leufvén A, Pehrson K (2001) Effect of changes in $\mathrm{pH}$ on the release of flavour compounds from a soft drink-related model system. Food Chemistry 74(4): 429-435.

62. Taylor RB (1998) Ingredients. In: Ashurst PR (Ed.), Chemistry and Technology of Soft Drinks and Fruit Juices. Sheffield Academic Press, England, pp. 16-54.

63. Dessirier JM, Simons C, Carstens MI, O Mahony M, Carstens E (2000) Psychophysical and neurobiological evidence that the oral sensation elicited by carbonated water is of chemogenic origin. Chemical Senses 25(3): 277-284.

64. Lubetkin S, Blackwell M (1988) The nucleation of bubbles in supersaturated solutions. Journal of Colloid and Interface Science 26: 610-615.

65. Wilt PM (1986) Nucleation rates and bubble stability in water- carbon dioxide solutions. Journal of Colloid and Interface Science 112(2): 530538. 
66. Barker GS, Jefferson B, Judd SJ (2002a) The control of bubble size in carbonated beverages. Chemical Engineering Science 57: 565-573.

67. Barker GS, Jefferson B and Judd SJ (2002 ${ }^{\mathrm{b}}$ ) Domestic carbonation process optimisation. Journal of Food Engineering 52: 405-412.

68. Descoins C, Mohamed M, Michel LM, James H (2006) Carbonation monitoring of beverage in a laboratory scale unit with on-line measurement of dissolved $\mathrm{CO}_{2}$. Food Chemistry 95(4): 541-553.

69. Abdelazim SA (2012) Studies On Using Some Medicinal Plants In The Production Of Natural Soft Drinks. Food Sci and Technol, Egypt.

70. Abdelazim SAA, Youssif MRG, Masoud MRM (2017) Micronutrients for Natural Carbonated and Non Carbonated Soft Drink. Journal of Nutritional Health \& Food Engineering 7(3): 1-10.
71. Abdelazim SA (2007) Technochemical and biological studies on some spices and their voltaile oils used in bakery. Food Sci. and Technol. Cairo University, Egypt.

72. http://lpi.oregonstate.edu/infocenter/minerals/phosphorus

73. Phillips S, Starkey LJ, Gray-Donald (2004) Food habits of Canadians: Food sources of nutrients for the adolescent sample. Can J Diet Pract Res 65(2): 80-84.

74. Soft drinks world (2003) Issues 15-20, Zenith International Publishing Ltd, Bath, United Kingdom. UK Bottled Water Report (2003) Section 1 from 1994 Zenith Guide, Zenith International Ltd, Bath, United Kingdom, pp. 98-106.

75. Ten-Cate JM, Imfeld T (1996) Dental erosion, summary. European Journal of Oral Science 104(2 Pt 2): 241-244.

This work is licensed under Creative

Commons Attribution 4.0 License

DOI: 10.19080/ARTOAJ.2018.14.555933
Your next submission with Juniper Publishers will reach you the below assets

- Quality Editorial service

- Swift Peer Review

- Reprints availability

- E-prints Service

- Manuscript Podcast for convenient understanding

- Global attainment for your research

- Manuscript accessibility in different formats

( Pdf, E-pub, Full Text, Audio)

- Unceasing customer service

Track the below URL for one-step submission https://juniperpublishers.com/online-submission.php 